\title{
F.J. Hitzhusen (Ed.), Economic Valuation of River Systems
}

\author{
Edward Elgard, Cheltenham UK, 2007, 217 pp, \\ ISBN 9781845426347
}

\author{
Marije Schaafsma
}

Received: 16 September 2008 / Accepted: 10 December 2008 / Published online: 8 January 2009

(C) The Author(s) 2009. This article is published with open access at Springerlink.com

This book presents the results of an eight-year research project (1998-2006) in the Great Lakes region of the US to develop methods and estimates of costs and benefits of water management. Many different types of water management and river restoration issues are addressed, including dam removal, mining problems and pesticide pollution. The book discusses the political economy of water management, the use of economic valuation results for market and non-market goods and services in political decision-making surrounding river management, including benefits capture and internalization, implementation of the beneficiary and polluter pays principle, and other equity issues related to the distribution of costs and benefits across various stakeholders. So, the book provides a wide variety of practical examples of economic assessments of river management projects.

The first part of the book provides an introduction to ecological engineering and the basic economic principles of environmental valuation of river systems. The impact of engineering works on ecosystems are described, and the scale at which, for instance, dams have ecologic and economic impacts due to ecosystem connectivity. One of the case studies illustrates how ecological modelling can improve the reliability of scenario building in valuation studies.

The next chapters present different case studies of surface water quality management and dam removal. In the contingent valuation (CV) studies, important topics pass in review, such as hypothetical bias, the effect of elicitation method, sensitivity to scope, order and context effects. Furthermore, illustrations are provided of the application of different marginal utility of income weights in the aggregation of willingness-to-pay (WTP) over the entire population and other distributional effects that policy scenarios can cause. Other studies combine revealed and stated preference methods, or apply benefits transfer to estimate a wide set of possible benefits. The book also includes an example of land-use modelling of non-point source pollution that accounts for upstream causes and downstream consequences.

Although the studies employ a rich array of cost-based, hedonic pricing, travel cost methods, and benefits transfer approaches, the overall scientific contribution of the book

M. Schaafsma $(\bowtie)$

Department of Environmental Economics, Institute for Environmental Studies (IVM), VU University,

Amsterdam, The Netherlands

e-mail: Marije.schaafsma@ivm.falw.vu.nl 
is somewhat limited. The quality of the case studies varies substantially between chapters and the reliability and validity of the results is sometimes hard to assess due to the fact that for example necessary survey details are often missing. The costs and benefits should therefore be interpreted as preliminary order of magnitude estimates. Moreover, the book does not build upon recent developments in stated preference methods, none of the case studies applied choice experiments.

Several examples are given of how water managers can deal with the limitations of the presented studies and values, such as ordering effects in CV studies, and the uncertainty surrounding both cost and benefit calculations, for example related to uncertainty regarding the spatial impact of dam removal or the time needed for ecosystem restoration. The authors argue that addressing the spatial distribution of benefits and costs across different political boundaries may stimulate cross-river corridor cooperation. By putting the case study results in such a wider perspective, the book offers policy-makers a nice range of valuation case studies and practical and illustrative guidance on the use of economic valuation results in cost-benefit analysis of river management.

Open Access This article is distributed under the terms of the Creative Commons Attribution Noncommercial License which permits any noncommercial use, distribution, and reproduction in any medium, provided the original author(s) and source are credited. 